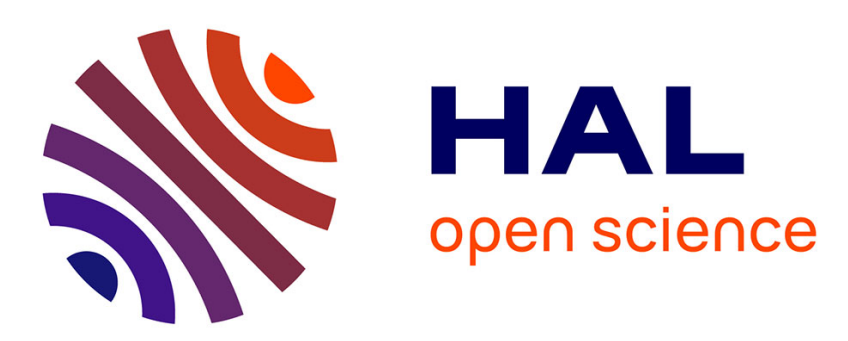

\title{
Cyclodextrin Cavity-Induced Mechanistic Switch in Copper-Catalyzed Hydroboration
}

Pinglu Zhang, Jorge Meijide suárez, Thomas Driant, Etienne Derat, Yongmin Zhang, Mickaël Ménand, Sylvain Roland, Matthieu Sollogoub

\section{- To cite this version:}

Pinglu Zhang, Jorge Meijide suárez, Thomas Driant, Etienne Derat, Yongmin Zhang, et al.. Cyclodextrin Cavity-Induced Mechanistic Switch in Copper-Catalyzed Hydroboration. Angewandte Chemie, 2017, 129 (36), pp.10961 - 10965. 10.1002/ange.201705303 . hal-01593597

\section{HAL Id: hal-01593597 https: / hal.sorbonne-universite.fr/hal-01593597}

Submitted on 26 Sep 2017

HAL is a multi-disciplinary open access archive for the deposit and dissemination of scientific research documents, whether they are published or not. The documents may come from teaching and research institutions in France or abroad, or from public or private research centers.
L'archive ouverte pluridisciplinaire HAL, est destinée au dépôt et à la diffusion de documents scientifiques de niveau recherche, publiés ou non, émanant des établissements d'enseignement et de recherche français ou étrangers, des laboratoires publics ou privés. 


\title{
Cyclodextrin cavity-induced mechanistic switch in copper-catalyzed hydroboration
}

\author{
Pinglu Zhang, Jorge Meijide Suárez, Thomas Driant, Etienne Derat, Yongmin Zhang, Mickaël \\ Ménand, Sylvain Roland, ${ }^{*}$ Matthieu Sollogoub*[a] \\ Sorbonne Université, UPMC Univ Paris 06, CNRS, Institut Parisien de Chimie Moléculaire (IPCM), UMR 8232, 4, place \\ Jussieu, 75005 Paris, France, E-mail: sylvain.roland@upmc.fr, matthieu.sollogoub@upmc.fr, Homepage: \\ http://www.ipcm.fr/Presentation,293
}

Cavity switch. NHC-capped cyclodextrin ligands, derived from $\alpha$ - and $\beta$-cyclodextrins give opposite regioselectivities in a copper-catalyzed hydroboration. This results from two different mechanisms: the conventional "parallel" one and a new "orthogonal" mechanism. The shape of the cavity was shown to induce both a regioselectivity and a mechanistic switch. The scope of interest of the encapsulation of a reactive center is therefore broadened by this study.

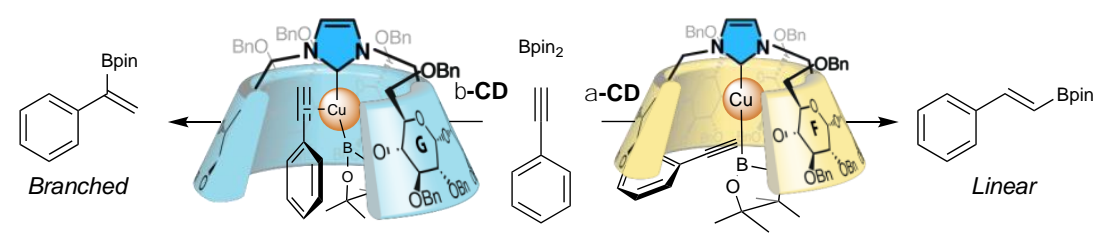

\begin{abstract}
NHC-capped cyclodextrin (ICyD) ligands, $\alpha$-ICyD and $\beta$-ICyD derived from $\alpha$ - and $\beta$-cyclodextrin respectively give opposite regioselectivities in a copper-catalyzed hydroboration. The site-selectivity results from two different mechanisms: the conventional "parallel" one and a new "orthogonal" mechanism. The shape of the cavity was shown not only to induce a regioselectivity switch but also a mechanistic switch. The scope of interest of the encapsulation of a reactive center is therefore broadened by this study.
\end{abstract}

Encapsulated metal complexes show distinctive behaviors resulting from the confinement of the metal. ${ }^{[1]}$ The cavity plays the role of second coordination sphere, which impacts reactivity and selectivity. ${ }^{[2-7]}$ Alterations in regioselectivity were observed with encapsulated metal catalysts in hydratation or hydroformylation reactions. ${ }^{[8-11]}$ An unusual coordination mode of the complex imposed by the confinement, or a controlled approach of the substrate imposed by sterics have been raised to explain the changes. Hence, regioselectivity is influenced by confinement of the reactive center but the reaction mechanism itself was not invoked. We present here a system in which not only the regioselectivity can be switched by only changing the size of a cavity but also the actual mechanism of the reaction. We also demonstrate another benefit of encapsulation in the discovery of new mechanisms.

In the framework of our studies on cyclodextrin (CD)-based metal catalysts, ${ }^{[12]}$ we developed $\mathrm{N}$-heterocyclic carbene (NHC)-capped CD complexes, called (ICyD)M, where the metal is literally wrapped by the CD scaffold. ${ }^{[13]}$ The position of an appended metal inside this cavity forces external ligands to be influenced by its shape to interact with the metal center. Thus, these particular structures were found to induce shapedependent enantio- and regioselectivities in gold-catalyzed cycloisomerisation reactions. ${ }^{[14]}$ Structural analyses of $(\alpha-I C y D) M$ and $(\beta-I C y D) M$ complexes, derived from $\alpha$ and $\beta-C D$, respectively, revealed significant differences in shape, in particular in the close surroundings of the metal. For instance, $\alpha-$ and $\beta$ ICyD-based complexes both present a groove leading to the metal, but for ( $\beta-\mathbf{I C y D}) \mathbf{M}$, a pit situated next to the metallic center is observed whereas the metal is tightly wrapped in ( $\alpha-\mathbf{I C y D}$ ) M (Figure 1). ${ }^{[14]}$ This suggests that a lateral approach to the metal may be conceivable for ( $\beta-\mathbf{I C y D}) \mathbf{M}$ complexes but precluded for 
$\alpha-I C y D$. We therefore wondered if we could rely on those differences to operate site-selective reactions based on differences of accessibility to the metal.

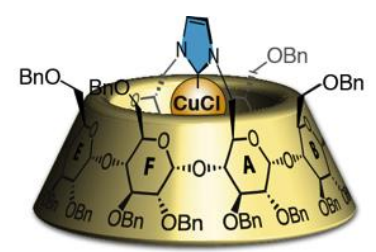

$(\alpha-\mathrm{ICyD}) \mathrm{CuCl}$

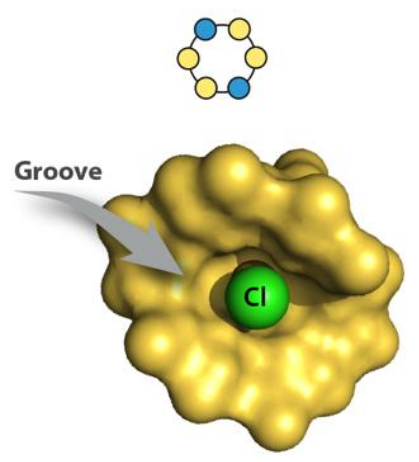

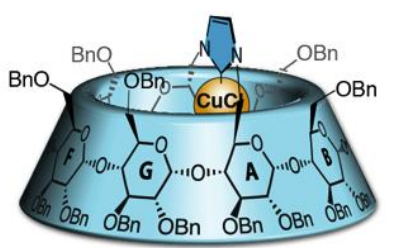

$(\beta-I C y D) C u C l$

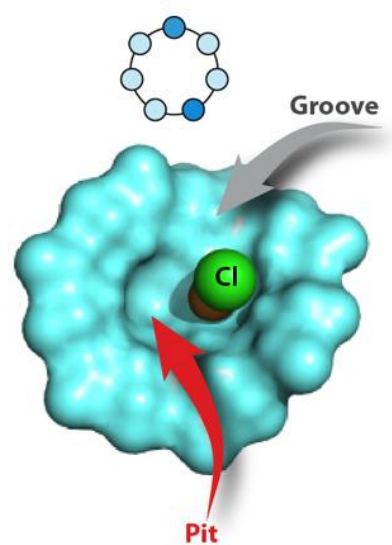

Figure 1. Structures and three-dimensional views of NHC-capped $\alpha$ and $\beta$-CD-derived copper(I) complexes.

For some time now, catalytic versions of the copper-mediated borylation of alkynes, using (Bpin) $)_{2}$ as boryl donor, ${ }^{[15,16]}$ have been developed. ${ }^{[17]}$ Remarkably, inversions of regioselectivities have been observed, particularly by introducing different copper ligands. ${ }^{[18-23]}$ For aryl-substituted terminal alkynes, and with nonbulky ligands, the selectivity is generally in favor of the linear adduct (or $\beta$-product, Scheme 1). ${ }^{[24]}$ An inversion of this trend was observed by Hoveyda with the bulky $\mathrm{N}$-aryl NHC ligand SIPr, which favored the formation of the branched adduct. ${ }^{[18]}$ Surprisingly, NHC-copper complexes bearing $\mathrm{N}$-alkyl substituted NHCs such as SIAd, of similar steric demand compared to $\mathrm{SIPr},{ }^{[25]}$ were found to give the opposite regioselectivity, leading to linear products, ${ }^{[18]}$ and demonstrating that the electronic properties of the NHC ligand may be predominant in controlling the reaction. Therefore, this reaction appeared as a good probe to observe the effect of a cavity, and more particularly of a CD cavity, on regioselectivity.

In this study, we compared $\alpha$ - and $\beta$-ICyD (Figure 1 ) of different cavity size but having identical $N$-alkylsubstituents. Much to our delight, the $\alpha-C D$ gave the linear borylated product as the major isomer whereas the $\beta$-CD gave the branched one (Scheme 1). Therefore, the $\alpha$-CD-derived NHC gave similar results than the bulky $N$-alkyl-substituted NHC SIAd, but the result obtained with the $\beta$-CD-derived NHC was unexpected for an $\mathrm{N}$-alkyl-substituted $\mathrm{NHC}$, suggesting a control by the cavity. Noteworthy, after a round of optimization, ${ }^{[26]}$ we found that the different experimental conditions to get Linear (RT) or Branched $\left(-20^{\circ} \mathrm{C}\right)$ derivatives described by Hoveyda were also the most efficient in our case. ${ }^{[18]}$ We then operated a review of various electronic effects on the alkyne aryl group in all ortho, meta and para positions. ( $\alpha-\mathbf{I C y D}) \mathbf{C u C l}$ consistently gave the linear product whereas $(\beta-I C y D) C u C l$ gave the branched compound as the major one. In the case of $(\beta-I C y D) C u C l$, a notable drop of regioselectivity is observed with methyl or OMe, ortho- and meta-substituted phenylacetylenes, suggesting that sterics of the substrate affects the regioselective outcome of the reaction. $(\boldsymbol{\alpha}-\mathbf{I C y D}) \mathbf{C u C l}$ and $(\beta-\mathbf{I C y D}) \mathbf{C u C l}$ gave also contrasted results with internal nonsymmetrical alkynes. In the case of the $\alpha$-CD-based catalyst, the selectivity remains in favor of the linear ( $\beta$-) compound regardless of the Me or Et alkyl group linked to the alkyne. In contrast, for the $\beta$-CD-based catalyst, increasing of the R goup size erodes the regioselectivity in favor of the branched $(\alpha-)$ compound and an inversion of selectivity was observed for the Et-derived phenylacetylene. 

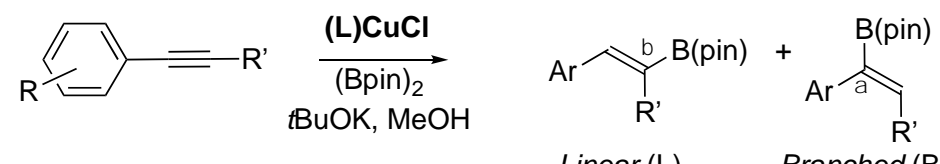

$$
\text { Linear (L) Branched (B) }
$$

\begin{tabular}{|c|c|c|c|c|c|c|}
\hline \multirow[b]{2}{*}{$\mathbf{R}$} & \multirow[b]{2}{*}{$\mathbf{R}^{\prime}$} & \multirow[b]{2}{*}{ Product } & \multicolumn{2}{|c|}{$\begin{array}{c}(\alpha-I C y D) C u C l \\
\text { at RT }\end{array}$} & \multicolumn{2}{|c|}{$\begin{array}{c}(\beta-I C y D) C u C l \\
\text { at }-20^{\circ} \mathrm{C}\end{array}$} \\
\hline & & & Yield & L:B ratio & Yield & L:B ratio \\
\hline $\mathrm{H}$ & $\mathrm{H}$ & 1 & $63 \%$ & $91: 9$ & $71 \%$ & $10: 90$ \\
\hline$p-\mathrm{MeO}$ & $\mathrm{H}$ & 2 & $67 \%$ & $93: 7$ & $87 \%$ & $10: 90$ \\
\hline$m-\mathrm{MeO}$ & $\mathrm{H}$ & 3 & $71 \%$ & $94: 6$ & $82 \%$ & $12: 88$ \\
\hline o-MeO & $\mathrm{H}$ & 4 & $55 \%$ & $93: 7$ & $64 \%$ & $46: 54$ \\
\hline$p-\mathrm{Me}$ & $\mathrm{H}$ & 5 & $49 \%$ & $92: 8$ & $66 \%$ & $8: 92$ \\
\hline$m-\mathrm{Me}$ & $\mathrm{H}$ & 6 & $48 \%$ & $93: 7$ & $78 \%$ & $14: 86$ \\
\hline o-Me & $\mathrm{H}$ & 7 & $39 \%$ & $93: 7$ & $74 \%$ & 19:81 \\
\hline$p-\mathrm{Cl}$ & $\mathrm{H}$ & 8 & $61 \%$ & $95: 5$ & $25 \%$ & $9: 91$ \\
\hline$m-\mathrm{Cl}$ & $\mathrm{H}$ & 9 & $70 \%$ & $97: 3$ & $40 \%$ & $6: 94$ \\
\hline $0-\mathrm{Cl}$ & $\mathrm{H}$ & 10 & $68 \%$ & $94: 6$ & $68 \%$ & $9: 91$ \\
\hline$p-\mathrm{F}$ & $\mathrm{H}$ & 11 & $48 \%$ & $86: 14$ & $65 \%$ & $4: 96$ \\
\hline$m-\mathrm{F}$ & $\mathrm{H}$ & 12 & $65 \%$ & $95: 5$ & $55 \%$ & $5: 95$ \\
\hline$O-F$ & $\mathrm{H}$ & 13 & $45 \%$ & $92: 8$ & $67 \%$ & $7: 93$ \\
\hline$p-\mathrm{CF}_{3}$ & $\mathrm{H}$ & 14 & $64 \%$ & $98: 2$ & $30 \%$ & $2: 98$ \\
\hline$m-\mathrm{CF}_{3}$ & $\mathrm{H}$ & 15 & $63 \%$ & $86: 14$ & $48 \%$ & $4: 96$ \\
\hline$o-\mathrm{CF}_{3}$ & $\mathrm{H}$ & 16 & $55 \%$ & $91: 9$ & $44 \%$ & $10: 90$ \\
\hline $\mathrm{H}$ & $\mathrm{Me}$ & 17 & $54 \%$ & $92: 8$ & $72 \%$ & $37: 63$ \\
\hline $\mathrm{H}$ & Et & 18 & $25 \%$ & $90: 10$ & $65 \%$ & $64: 36$ \\
\hline
\end{tabular}

Scheme 1. Model reaction to study the regioselectivity induced by the CD cavity. $(L)=$ CD-NHC ligands $\boldsymbol{\alpha}-\mathrm{ICyD}$ or $\boldsymbol{\beta}-$ ICyD.

The copper-mediated borylation of alkynes is thought to start with activation of the $(\mathrm{L}) \mathrm{CuCl}$ pre-catalyst by tBuOK to form a (L)Cu-OtBu adduct which reacts with (BPin) ${ }_{2}$ to give a (L)Cu-Bpin complex. ${ }^{[15-18,27,28]} \mathrm{Next}$, the formation of a vinyl copper species resulting from concerted syn borylcupration of the alkyne was proposed. ${ }^{[29]}$ The regioselectivity of the reaction is influenced at this step both by the initial approach of the alkyne on the copper atom to form the $\pi$-complex (la or Ib Scheme 2) and by the TS (Ila or Ilb) of the insertion step. This "parallel" lateral approach of the alkyne to the NHC-Cu-B bond was extensively investigated by theoretical calculations. ${ }^{[18,30]}$ Generally, less hindered and more electronically rich ligands favor linear product formation, whereas more sterically hindered less electron-donating ligands give branched products. However, this last statement seems to be in contradiction with our results, as the most sterically hindered ligand $\alpha-I C y D$ affords linear products, when the larger $\beta$-CD derivative favors branched compounds. NMR analyses of all $(\mathrm{L}) \mathrm{CuCl},(\mathrm{L}) \mathrm{Cu}-\mathrm{O} t \mathrm{Bu}$, and $(\mathrm{L}) \mathrm{Cu}-\mathrm{Bpin}$ intermediates for both $\boldsymbol{\alpha}-\mathrm{ICyD}$ and $\beta$-ICyD ligands (see SI), showed deshielding of $\mathrm{H}-5 \mathrm{~s}$ characteristic of the metal inside the cavity. ${ }^{[13,14]}$ This demonstrates that the syn borylcupration step, which controls regioselectivity, is forced to take place inside the cavity with (ICyD)CuBpin intermediates. 


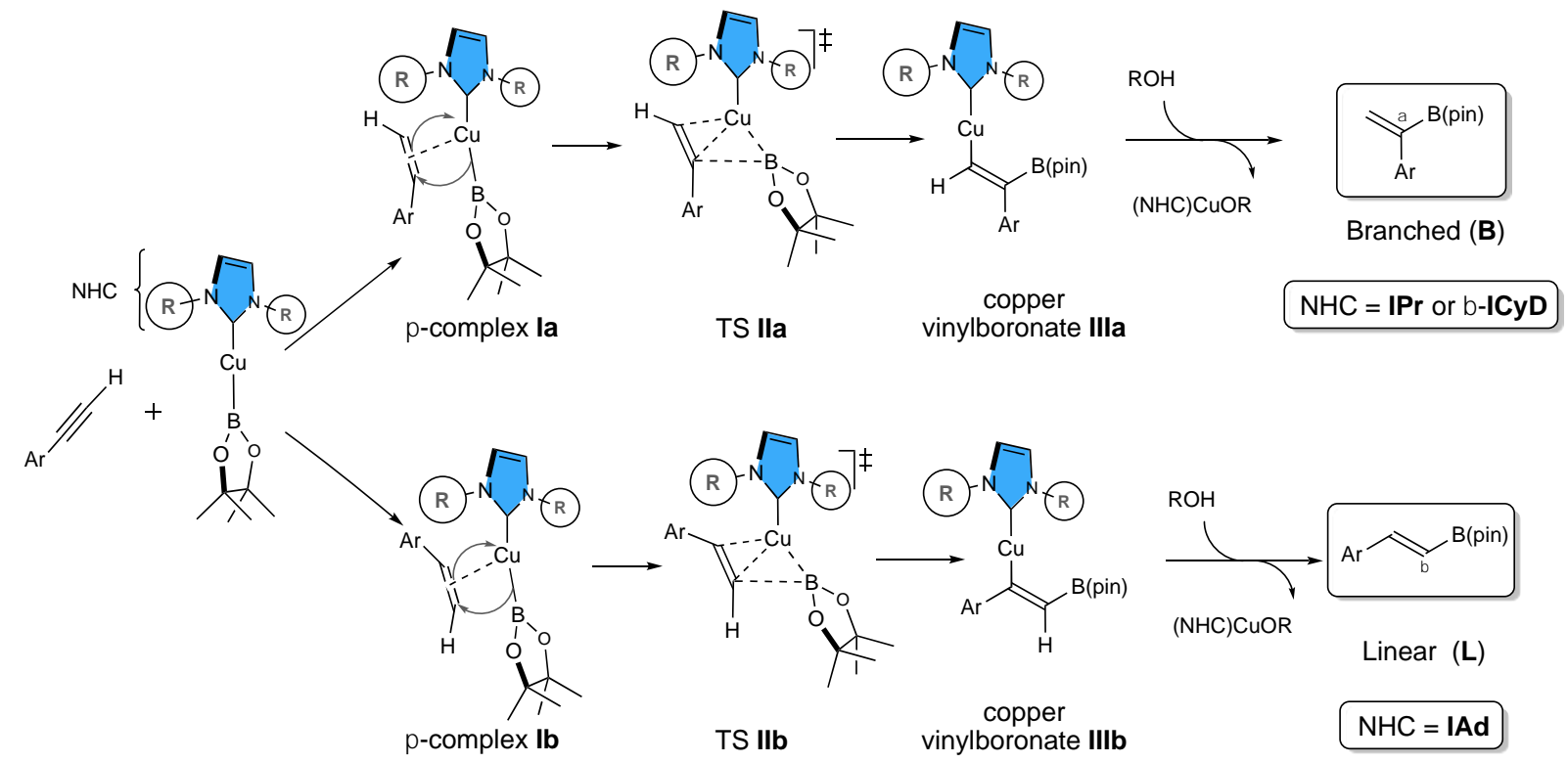

Scheme 2. Proposed pathways for the formation of the branched or linear adducts with (NHC)CuCl.

We found next by molecular modeling using DFT calculations (see SI) that the alkyne can only access the copper atom of $(\boldsymbol{\beta}-\mathrm{ICyD}) \mathrm{CuBpin}$ when the phenyl group is positioned next to the entrance of the cavity to form $\pi$-complex la. (Scheme 2 and Figure 2). Therefore, the approach of phenylacetylene is clearly governed by the shape of the cavity that imposes a reverse approach compared to the reported $\mathrm{N}$-alkyl-substituted $\mathrm{NHCs}$, and overrules the electronic effects, resulting in high selectivity for the branched isomer. This is consistent with the low sensitivity of the reaction to the electronic effects of the Ar substituents but rather to their steric hindrance (Scheme 1).

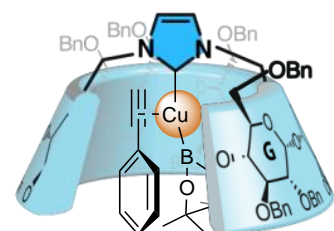

( -ICyD)CuBpin-HCCPh -complex la

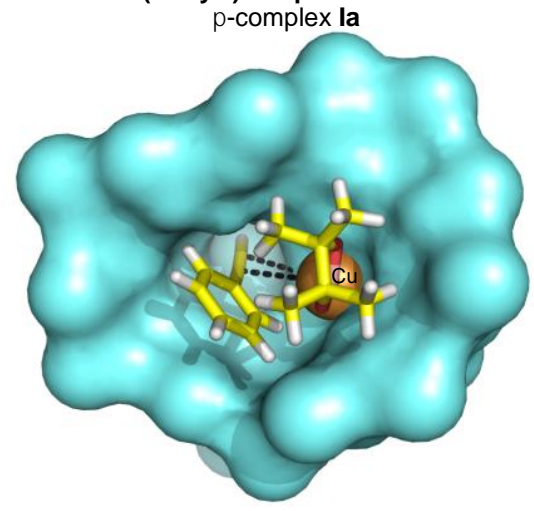

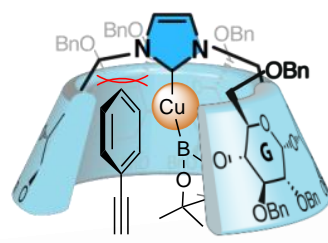

( -ICyD)CuBpin-HCCPh -complex Ib

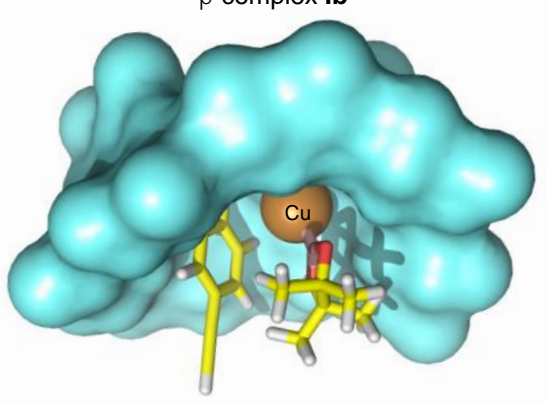

Figure 2. DFT Modeling of the two possible parallel approaches of phenylacethylene to the Ccarbene-Cu-B bond with $(\beta-I C y D) C u B p i n$. In the right approach with the phenyl group inside the cavity ( $\pi$-complex Ib), the alkyne cannot reach the reactive copper center.

The results obtained with $\alpha-I C y D$ are therefore puzzling, as, when considering the "parallel" approach, formation of the linear product would imply an inclusion of the phenyl in the cavity deep enough to bring the triple bond next to the copper atom to form $\mathbf{I b}$. This approach that was sterically unfavorable with the wider $\boldsymbol{\beta}$ - 
ICyD, is even more difficult to conceive with the tighter $\alpha-I C y D$. In fact, our initial attempts to theoretically study the mechanism failed. By trying to approach the alkyne towards the metal, we observed that the steric hindrance around the copper atom clearly prevented alkyne coordination. We therefore changed our strategy and decided to operate a backward study. We assumed that the alkenylcopper intermediate (IIlb) was formed and modeled it. Then, we imposed an iterative shortening of the of $\mathrm{Cu}-\mathrm{B}$ bond. In doing so, we were able to observe the passage through a transition state involving coordination of the metal center with the boron atom and both carbons involved. Further reduction of the $\mathrm{Cu}-\mathrm{B}$ distance resulted in the release of the alkyne and revealed an original quasi-perpendicular approach at the level of the Cu-B bond (Ic in Scheme 3). The confinement of the metal center inside the cavity of $\alpha$-ICyD therefore not only induces a switch of regioselectivity but also of mechanism from "parallel" to "orthogonal" (Schemes 3 and 4).

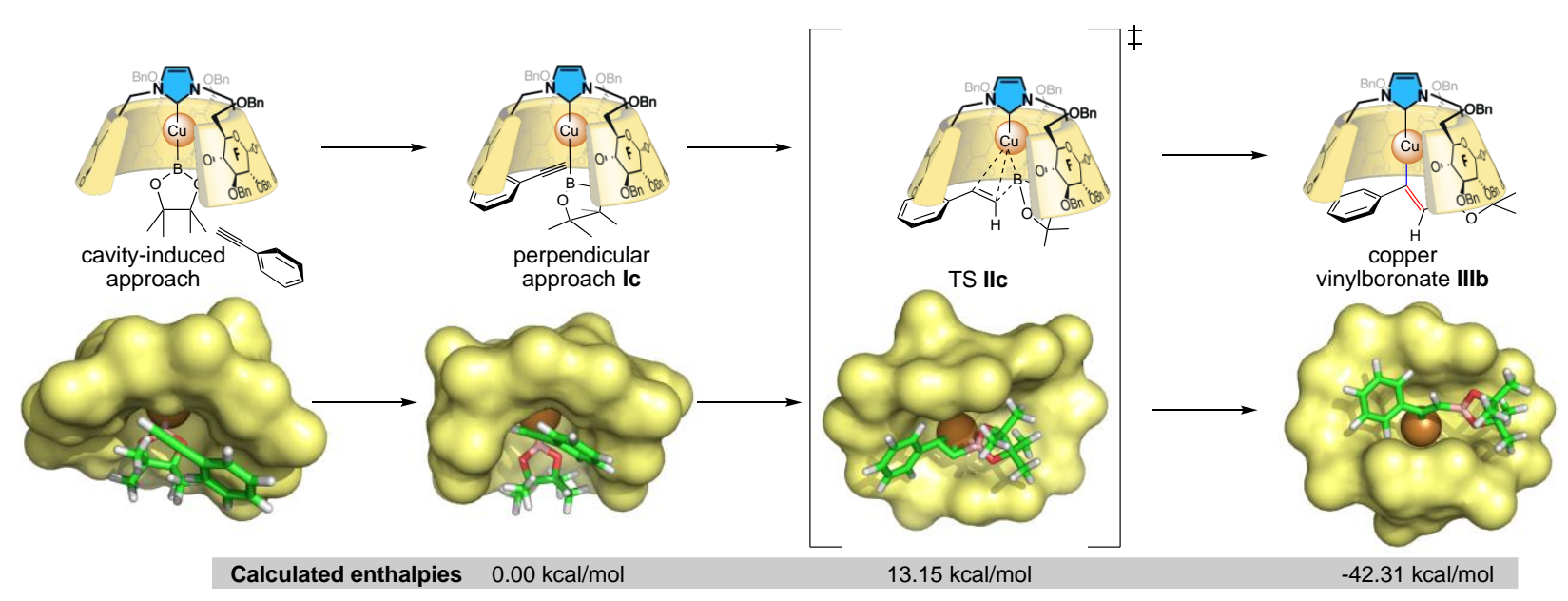

Scheme 3. Proposed "orthogonal" mechanism for the borylation reaction with $\alpha$-ICyD with the corresponding calculated enthalpies.

To explain the regioselectivity of the reaction, we examined in detail the inter-atomic distances in the corresponding TS Ilc. It appears that the B-C $\beta$ bond is rather short $(1.70 \AA)$ whereas the $\mathrm{C} \alpha$-Cu bond is long $(2.16 \AA)$. This observation implies the development of a negative charge at $\mathrm{C} \alpha$. The regioselectivity in favor of the Linear product is therefore probably governed by the development of this negative charge which is stabilized by the phenyl (Scheme 4) ${ }^{[27]}$ In light of the two mechanisms proposed here, it is also possible to rationalize the results obtained with internal alkynes. For $\alpha-I C y D$ the mechanism remains the same and the linear product is still the major one, although the yield decreases probably due to steric hindrance preventing access to the metal. The regioselectivity in favor of the attachment of the boron atom next to the alkyl chain rather than next to the phenyl group can also be accounted for in light of the proposed transition state (TS IIc). Indeed, the development of a negative charge is more stabilized by a phenyl than an alkyl group. ${ }^{[27]}$ In the case of $\beta-I C y D$, the adjunction of a methyl and a fortiori an ethyl group on the alkyne makes the triple bond less accessible to the metal in the case of the "parallel" mechanism. In this case the competitive "orthogonal" mechanism leading to the linear product for the same electronic reasons as for $\alpha$-ICyD can be considered. We therefore propose that a switch in mechanism from "parallel" to "orthogonal" in the $\beta$-ICyD case explains the reversal of regioselectivity from branched to linear for hindered internal alkynes. 


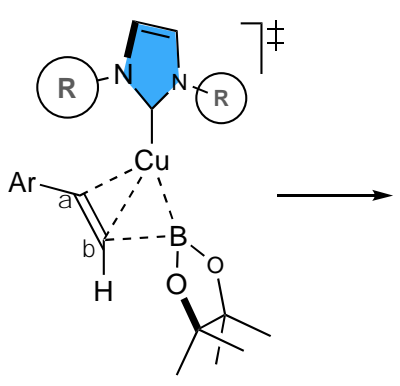

TS Ilb

$\mathrm{NHC}=\mathbf{I A d}$

"parallel" approach (previous studies)

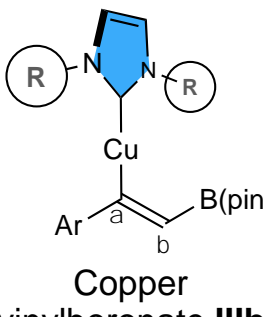

vinylboronate IIIb

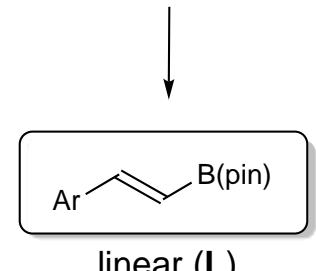

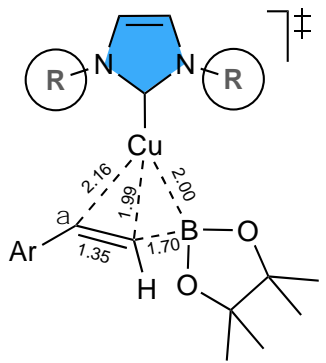

TS IIc

$\mathrm{NHC}=-\mathrm{ICyD}$

"orthogonal" approach

(this study)

Scheme 4. Mechanistic switch from "parallel" to "orthogonal" imposed by the cavity.

We showed that ICyD ligands could be used for regioselective copper-catalyzed hydroboration. The outcome of the reaction is governed by the nature of the CD, $\alpha-C D$ giving the Linear product, while $\beta-C D$ derivative gives the Branched product with terminal alkynes. In fact, it is the difference in shape of those two catalysts that imposes the site-selectivity, which results from two different mechanisms: the conventional "parallel" mechanism and a new one uncovered by this study, a so-called, "orthogonal" mechanism. In this particular case, the shape of the cavity not only induces a regioselectivity switch but also a mechanistic switch. ${ }^{[31]}$ Furthermore, the orthogonal approach is a new mechanistic proposal for this reaction that might be considered in other cases, for example for the reaction operated on a metallic copper surface where the metal center is also hindered. ${ }^{[32]}$ The scope of interest of the encapsulation of a reactive center was broadened here, as it revealed a different mechanism in a well-studied reaction, a feature that probably exists in other systems.

\section{Acknowledgements}

MS thanks Professor Amir Hoveyda for a fruitful discussion that led to this work. PZ thanks the CSC for PhD grant. ED thanks Sven Klumpe for preliminary investigations on the mechanism. The authors thank LabEx MiChem part of French state funds managed by the ANR within the Investissements d'Avenir programme under reference ANR-11-IDEX-0004-02, Cyclolab (Hungary) and Roquette (France) for generous supply of $\alpha-$ and $\beta$-CDs respectively.

Keywords: Cyclodextrins, Metallo-pockets; Molecular shape; Cavity; N-heterocyclic carbenes (NHC); Catalysis

[1] M. Raynal, P. Ballester, A. Vidal-Ferran P. W. N. M. Van Leeuwen, Chem. Soc. Rev. 2014, 43, 1734; C. J. Brown, F. D. Toste, R. G. Bergman, K. N. Raymond, Chem. Rev. 2015, 115, 3012; S. H. A. M. Leenders, R. Gramage-Doria, B. de Bruin, J. N. H. Reek, Chem. Soc. Rev. 2015, 44, 433

[2] M. A. Sarmentero, H. Ferandez-Pérez, E. Zuidema, C. Bo, A. Vidal-Ferran, P. Ballester, Angew. Chem. Int. Ed. 2010, 49, 7489

[3] Z. J. Wang, C. J. Brown, R. G. Bergman, K. N. Raymond, F. D. Toste, J. Am. Chem. Soc. 2011, 133, 7358

[4] C. Gibson, J. Rebek, Org. Lett. 2002, 4, 1887; P. F. Kuijpers, M. Otte, M. Dürr, I. Ivanovic-Burmazovic, J. N. H. Reek, B. de Bruin, ACS Catal. 2016, 6, 3106; M. Otte, ACS Catal. 2016, 6, 6491

[5] A. C. H. Jans, A. Gómez-Suarez, S. P. Nolan, J. N. H. Reek, Chem. Eur. J. 2016, 22, 14836

[6] C. Zhao, Q.-F. Sun, W. M. Hart-Cooper, A. G. DiPasquale, F. D. Toste, R. G. Bergman, K. N. Raymond, J. Am. Chem. Soc. 2013, 135, 18802

[7] D. Zhang, K. Jamieson, L. Guy, G. Gao, J.-P. Dutasta, A. Martinez, Chem. Sci. 2017, 8, 789

[8] A. Cavarzan, A. Scarso, P. Sgarbossa, G. Strukul, J. N. H. Reek, J. Am. Chem. Soc. 2011, 133, 2848

[9] V. Bocokic, A. Kalkan, M. Lutz, A. L. Spek, D. T. Gryko, J. N.H. Reek, Nat. Commun., 2013, 4, 2670 
[10] C. García-Simoń, R. Gramage-Doria, S. Raoufmoghaddam, T. Parella, M. Costas, X. Ribas, J. N. H. Reek, J. Am. Chem. Soc. 2015, 137, 2680

[11] M. Jouffroy, R. Gramage-Doria, D. Armspach, D. Sémeril, W. Oberhauser, D. Matt, L. Toupet, Angew. Chem., Int. Ed. 2014, 53, 3937

[12] S. Guieu, E. Zaborova, Y. Blériot, G. Poli, A. Jutand, D. Madec, G. Prestat, M. Sollogoub, Angew. Chem. Int. Ed. 2010, 49, 2314; E. Zaborova, J. Deschamp, S. Guieu, Y. Blériot, G. Poli, M. Ménand, D. Madec, G. Prestat, M. Sollogoub, Chem. Commun. 2011, 47, 9206; F.-X. Legrand, M. Ménand, M. Sollogoub, S. Tilloy, E. Monflier, New J. Chem. 2011, 35, 2061; M. Guitet, F. Marcelo, S. Adam de Beaumais, Y. Zhang, J. Jiménez-Barbero, S. Tilloy, E. Monflier, M. Ménand, M. Sollogoub, Eur. J. Org. Chem. 2013, 3691

[13] M. Guitet, P. Zhang, F. Marcelo, C. Tugny, J. Jiménez-Barbero, O. Buriez, C. Amatore, V. Mouriès-Mansuy, J.-P. Goddard, L. Fensterbank, Y. Zhang, S. Roland, M. Ménand, M. Sollogoub, Angew. Chem. Int. Ed. 2013, 52, 7213

[14] P. Zhang, C. Tugny, J. Meijide Suárez, M. Guitet, E. Derat, N. Vanthuyne, Y. Zhang, O. Bistri, V. MourièsMansuy, M. Ménand, S. Roland, L. Fensterbank, M. Sollogoub, Chem 2017, 3, 174

[15] K. Takahashi, T. Ishiyama, N. Miyaura, J. Organomet. Chem. 2001, 625, 47

[16] J.-E. Lee, J. Kwon, J. Yun, Chem. Commun. 2008, 733; H. R. Kim, I. G. Jung, K. Yoo, K. Jang, E. S. Lee, J. Yun, S. U. Son, Chem. Commun. 2010, 46, 758; H. R. Kim, J. Yun, Chem. Commun. 2011, 47, 2943

[17] J. Yun, Asian J. Org. Chem. 2013, 2, 1016; R. Barbeyron, E. Benedetti, J. Cossy, J.-J. Vasseur, S. Arseniyadis, M. Smietana, Tetrahedron, 2014, 70, 8431; T. Fujihara, K. Semba, J. Terao, Y. Tsuji, Catal. Sci. Technol. 2014, 4, 1699; H. Yoshida, ACS Catal. 2016, 6, 1799

[18] H. Jang, A. R. Zhugralin, Y. Lee, A. H. Hoveyda, J. Am. Chem. Soc. 2011, 133, 7859

[19] J. K. Park, B. A. Ondrusek, D. T. McQuade, Org. Lett. 2012, 14, 4790

[20] Y. D. Bidal, F. Lazreg, C. S. J. Cazin, ACS Catal. 2014, 4, 1564

[21] J. S. da Costa, R. K. Braun, P. A. Horn, D. S. Lüdtke, A. V. Moro, RSC Adv. 2016, 6, 59935

[22] W. Su, T.-J. Gong, Q. Zhang, Q. Zhang, B. Xiao, Y. Fu, ACS Catal. 2016, 6, 6417

[23] Z.-J. Yaoa, S. Honga, W. Zhanga, M. Liua, W. Deng, Tetrahedron Lett. 2016, 57, 910

[24] We will use Linear and Branched products instead of $\square$ and $\square$ products, not to confuse the reader with $\alpha-$ and $\beta$-CDs nomenclature.

[25] A. Poater, B. Cosenza, A. Correa, S. Giudice, F. Ragone, V. Scarano, L. Cavallo, Eur. J. Inorg. Chem. 2009, 1759

[26] We found that ( $\boldsymbol{\alpha}-\mathbf{I C y D}) \mathbf{C u C l}$ worked well at R.T. At this temperature ( $\beta-I C y D) C u C l$ gave a faster reaction $(2 \mathrm{~h}$ instead of $12 \mathrm{~h}$ ) and a 75:25 ratio in favor of the Branched compound. We lowered the reaction temperature to $20^{\circ} \mathrm{C}$ for this catalyst to obtain a 90:10 ratio. This difference of reactivity is probably linked to the accessibility of the metal in the cavity.

[27] J. H. Moon, H.-Y. Jung, Y. J. Lee, S. W. Lee, J. Yun, J. Y. Lee, Organometallics 2015, 34, 2151

[28] D. S. Laitar, P. Müller, J. P. Sadighi, J. Am. Chem. Soc. 2005, 127, 17196

[29] D. S. Laitar, E. Y. Tsui, J. P. Sadighi, Organometallics 2006, 25, 2405

[30] J. H. Moon, H.-Y. Jung, Y. J. Lee, S. W. Lee, J. Yun, J. Y. Lee Organometallics 2015, 34, 2151

[31] Selected examples: Y. Pocker, B. P. Ronald, J. Am. Chem. Soc. 1980, 102, 5311; M. Chabanas, V. Vidal, C. Copéret, J. Thivolle-Cazat, J.-M. Basset, Angew. Chem. Int. Ed. 2000, 39, 1962; S. Ma, Z. Shi, Chem. Commun. 2002, 540; C. J. Abraham, D. H. Paull, T. Bekele, M. T. Scerba, T. Dudding, T. Lectka, J. Am. Chem. Soc. 2008, 130, 17085; M. M. Hansmann, M. Rudolph, F. Rominger, A. S. K. Hashmi, Angew. Chem. Int. Ed. 2013, 52, 2593; D. Carrasco, M. García-Melchor, J. A. Casares, P. Espinet, Chem. Commun. 2016, 52, 4305

[32] J. Zhao, Z. Niu, H. Fu, Y. Li, Chem. Commun. 2014, 50, 2058 
